\title{
Dental care for homeless issue attracts BDA controversy
}

Problems over how dentists provide care to homeless people have surfaced in a controversial debate in the national press recently involving BDA Chair Mick Armstrong.

Armstrong sent an email to a colleague that was mistakenly copied and sent to Labour MP Stella Creasy on the subject in which he made reference to homeless people as 'no-hopers' in the context of how the current dental contract makes it difficult to treat homeless patients.

The story was covered in some parts of the media including the Guardian newspaper ${ }^{1}$ on 28 July 2018 and the Huffington Post and was also was the subject of a piece in a Nursing Times magazine's 'Heroes and Villains of the month' article, ${ }^{2}$ which referred to Armstrong in the latter capacity.

In the email, Armstrong is quoted as saying: 'These are difficult patients who rarely complete a course of treatment and attend irregularly if at all. If we took in all the no-hopers who ring us ... I suspect we'd miss our targets by a country mile.'

After an exchange with Creasy, Armstrong issued a statement saying: 'I regret the intemperate wording I used in my exchange with Stella Creasy. The language was inappropriate but born of the frustration that all NHS dentists in England feel working under a

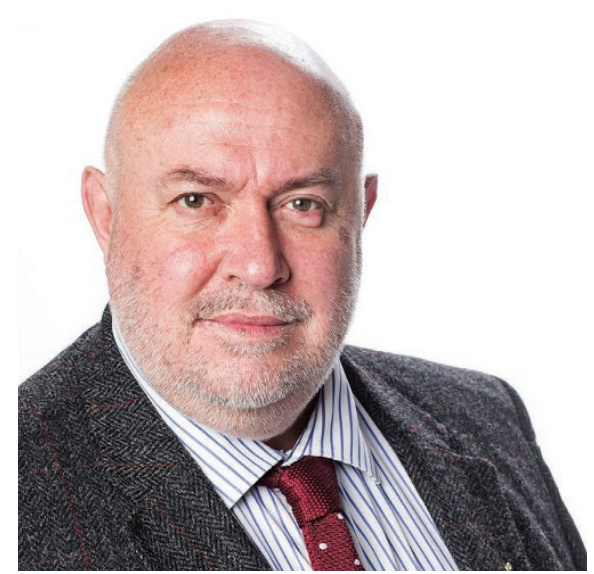

BDA Chair Mick Armstrong

contract that's decisively failed both patients and practitioners.

'I work as an NHS dentist near Wakefield, and like many colleagues, I treat homeless patients, but it is not easy under the current contract. The NHS effectively caps the number of patients we can treat and fails to cater for those most in need. Dentists are desperate for a system that will allow them to put their patients first.

'The BDA has long championed vulnerable patients, and has argued to ensure that they have access to services that are really tailored to their needs. Sadly any headway seems impossible under the existing contract.'
Groundswell, a charity that helps homeless people, published a report ${ }^{3}$ in May 2017 which said that $70 \%$ of people reported having lost teeth since they had been homeless, with $30 \%$ experiencing dental pain at the time they were being interviewed.

The BDA said the current target-driven 2006 NHS dental contract provided funding for little over half the English population and high street NHS dentists faced significant barriers in treating homeless patients in particular, for example they were required to provide the NHS with an address for a patient.

The union has called for funding of dental appointment slots, especially for homeless people, which once booked, would be funded whether patients attended or not, so dentists attempting to treat these groups were not penalised; and changes to NHS forms to enable a dentist to be paid for delivering treatment where the patient does not have an address.

1. Crerar P. Homeless people make us miss NHS targets, says UK's chief dentist. The Guardian 28 July 2018. https://www.theguardian.com/society/2018/jul/28/ homeless-people-make-us-miss-nhs-targets-says-ukschief-dentist (accessed on 21 August 2018).

2. Ford S. Who are our heroes and villains for July 2018? Nursing Times. 6 August 2018. https://www.nursingtimes. net/news/politics/who-are-our-heroes-and-villains-forjuly-2018/7025490.article (accessed on 22 August 2018).

3. Groundswell. Healthy Mouths. May 2017. http://ground swell.org.uk/wp-content/uploads/2017/10/Groundswell-Healthy-Mouths-Report-Final.pdf (accessed on 5 September 2018).

\section{MPs say relax rules over use of e-cigarettes to tackle 'deadly' smoking}

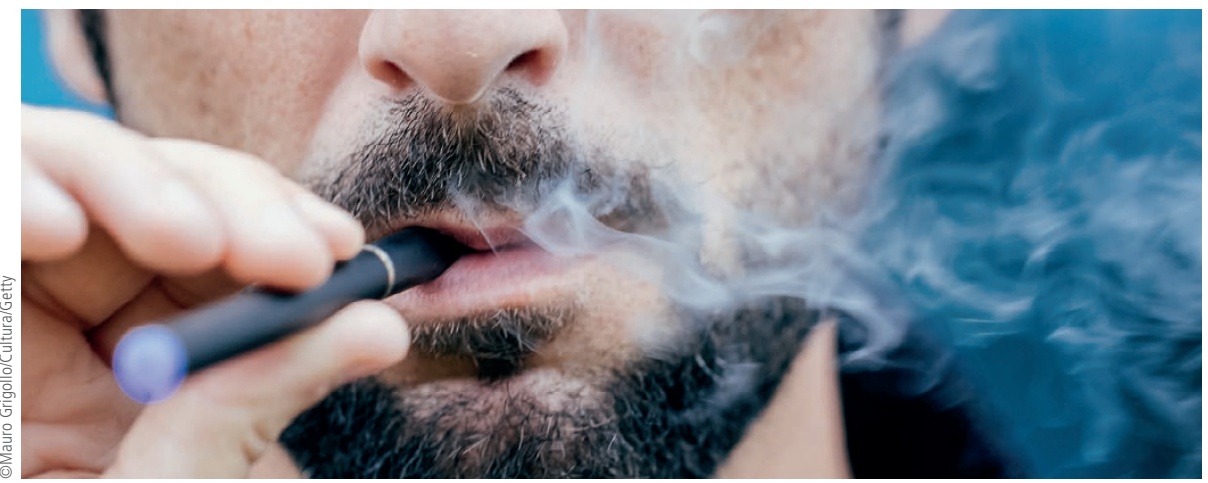

Regulations over the use of electronic (e) cigarettes should be relaxed to encourage more use of these devices as a stop smoking tool and to help prevent cancer, according to MPs on an influential committee.

MPs on the House of Commons Science and Technology Committee published a report $^{1}$ on e-cigarettes on 17 August 2018 which reviews the current evidence base on the harmfulness of e-cigarettes compared to conventional cigarettes and current policies.

The report says that e-cigarettes are estimated to be $95 \%$ less harmful than conventional cigarettes and are too often overlooked as a stop smoking tool by the NHS.
Therefore, regulations should be relaxed relating to e-cigarettes' licensing, prescribing and advertising of their health benefits, while levels of taxation and their use in public places be reconsidered.

MPs concluded that e-cigarettes should not be treated in the same way as conventional cigarettes. The two leading causes of mouth cancer in the UK are tobacco and alcohol.

During the Committee's inquiry into the subject, MPs had heard from witnesses giving evidence that e-cigarettes were not a significant gateway, including for young non-smokers, to conventional smoking and did not pose a significant risk through second-hand inhalation.

Around 2.9 million people in the UK currently use e-cigarettes, and it has been estimated that about 470,000 people are using them as an aid to stop smoking. 